\title{
CIÊNCIAS DA COMUNICAÇÃo, ÁREA INTERDISCIPLINAR *
}

\author{
ANíbal AlVEs **
}

\section{RESUMO}

Partindo da actualidade e relevância das questōes de comunicação, procura-se neste artigo, em primeiro lugar, evocar alguns factores fundamentais na constituição da área científica da comunicação, tais como os mass media, a teoria da comunicação, o estudo da comunicação no quadro das ciências sociais e no quadro das ciências humanas e da linguagem. À luz do panorama delineado, propõe-se a concepção interdisciplinar das Ciências da Comunicação.

\section{Novidade e relevância do Estudo da "Comunicação»}

No final dos anos 80 e início dos 90 surgiu em Portugal um inesperado número de cursos superiores no âmbito da "Comunicação Social» ou "Ciências da Comunicação». No relatório que apresentámos à Conferência de Siena (1995), «L'Avenir des Sciences de la Communication en Europe» 1, referíamos um conjunto identificado de dez licenciaturas e catorze bacharelatos, uma contagem que se revelaria aquém dos efectivos. «O milagre da

* Texto de enquadramento do programa da disciplina de Teorias da Comunicação do curso de Comunicação Social da Universidade do Minho (1996).

** Professor do Departamento de Ciências da Comunicação, Instituto de Ciências Sociais, Universidade do Minho.

1 A. AlVES, "Les Sciences de la Communication au Portugal» in SIGMA, European Universities Networks, L'Avenir des Sciences de la Communication en Europe, Sienne, 1995, pp. 180-205. 
multiplicação dos cursos de comunicação» suscitou viva reacção. Deve notar-se que a reflexão do autor da feliz expressão citada (ela própria marcada pela ironia), Mário Mesquita, destacou-se do tom geral entre o espanto e o menosprezo, com uma análise exemplar pelo rigor informativo e pela interpretação contextualizada ${ }^{2}$. Permanece o facto de que a explosão dos cursos de Comunicação foi recebida com atitudes de reserva, de rejeição, ou pelo menos de desconfiada admiração.

Esta admiração não será muito diferente daquela que pessoalmente temos experimentado em interlocutores a quem respondemos à sua pergunta sobre a disciplina ou matéria que ensinamos na Universidade: "Professor de Comunicação», «de Comunicação Social»? Mas, existe um curso universitário sobre isso? Mais de trinta cursos superiores? $\mathrm{O}$ espanto não é necessariamente movimento de rejeição. Pode até, pelo contrário, estimular a interrogação, a busca de sentido e a sua descoberta. É nessa perspectiva que desejamos aqui tomá-lo.

A relevância da comunicação nos processos vitais das actuais sociedades é facilmente reconhecível e justifica a sua redundante manifestação bem como a admiração que esta suscita. Assim preeminente na vida social, não podia a comunicação deixar de motivar a consideração e interesse dos agentes sociais, e designadamente das instituições de ensino especializado. Aqui se encontra o outro ponto de interrogação e quiçá de suspeita: a comunicação humana é certamente dimensão importante da vida social; mas poderá constituir objecto de saber e de tratamento científico? A dúvida espontânea revela uma atitude frequente e bem conhecida em relação às ciências sociais e humanas. Costuma mesmo identificar-se esta atitude como obstáculo ao conhecimento científico. E assim é na medida em que o conhecimento do senso comum, ou não reconhece sequer o objecto específico em questão, dada a sua «transparência», ou lhe atribui carácter completo, o que dispensa o exame crítico, apanágio da metodologia científica. $O$ humilde e progressivo caminho histórico do conhecimento humano ilustra bem o carácter ilusório dos saberes que se autoatribuíram carácter definitivo. Entre estes se encontram não apenas os que se fecharam no conhecimento comum mas também não poucos que, reclamando-se da ciência, se arrogaram a ilusória evidência e segurança daqueles.

No entanto, a resistência do leigo perante o estatuto científico e académico de questões como a comunicação é susceptível de interpretação menos simplista. Em vez de significar auto-suficiência que dispensaria tratamento científico julgado inadequado, aquela dúvida exprimiria perple-

2 M. MEsquita, «A Educação para o Jornalismo», Comunicação ao II Congresso dos Jornalistas de Língua Portuguesa, Rio de Janeiro, Dezembro de 1994. 
xidade perante a tentativa de abordar a comunicação humana com metodologia científica e enquadramento académico. A esta luz, a dúvida sobre o estudo científico da comunicação deixa de ser obstáculo para se tornar estímulo crítico a sublinhar a permanente tensão entre o projecto compreensivo de uma disciplina científica como Ciências da Comunicação e o seu complexo objecto fenomenal, manifestação histórica do ser e devir humanos.

É, por outro lado, natural que o estudo instituído da comunicação ainda surpreenda em razão da sua novidade e carácter recente. Não que a comunicação tenha sido alheia ao interesse e estudo das sociedades e civilizações que nos precederam. É notório que elementos e dimensões fundamentais do processo comunicativo mereceram de pensadores antigos e modernos estudos de tal rigor e fecundidade que, ainda hoje, estes guiam a nossa indagação. Lembremos designadamente os problemas da linguagem e do conhecimento abordados nos estudos da língua, da filosofia, do direito, da teologia, da moral e da política. Como referia Umberto Eco em comentário a um artigo de $\mathrm{R}$. Jakobson sobre a semiótica e, portanto, sobre a comunicação, o estudo desta apresenta uma impressionante genealogia: "a science dealing with signes and with processes of communication has an impressive pedigre» 3 . É no entanto manifesto que a comunicação como área de estudo e campo de acção específicos, é do nosso século. Alguém notou com sentido que a "comunicação» suscitou no século XX o entusiasmo que a «energia» despertou no século XIX.

De modo especial pode associar-se a emergência da comunicação ao clima de reconstrução que animou o período imediato à II Grande Guerra Mundial. Como se, simbolicamente, as sociedades, traumatizadas pela hecatombe da destruição e pelo horror dos holocaustos, almejassem na comunicação um antídoto reparador e capaz de inspirar novo alento civilizacional. É então que surgem as obras de C. Shannon e de N. Wiener ${ }^{4}$ que se tornariam referência de primeira ordem para o estudo da comunicaçāo. Por outro lado, é também nesta altura que é publicado o célebre artigo de Lasswell 5 "The Structure and Function of Communication in Society", e se tornam conhecidas as pesquisas de P. Lazarsfeld ${ }^{6}$ sobre os

3 U. Eco, «Preface» in Chatman, S., Eco, U., KLINKenberg, J.-M., (Ed.s), a Semiotic Landscape, The Hague, Mouton, 1979, p. VI.

4 N. WIENER, Cybernetics or Control and Communication in the Animal and the Machine, Paris, Librairie Herman, 1948.

$5 \mathrm{H}$. LASSWEL, "The Structure and Function of Communication in Society», in The Communication of Ideas, BRISON, L., ed., New York, 1948.

6 P. Lazarsfeld et al., The People's Choice, N. York, Columbia, Univ. Press, 1948. 
processos de comunicação e de influência a propósito das campanhas para a eleição presidencial (a de 1940 e a de 1948).

K. Lewin, em 1945, introduzia a sua orientação da pesquisa-acção no Massachusetts Institute of Technology e lançava, em seguida, o projecto dos Laboratórios de «Training Group», extraordinário alfobre de cientistas que animariam a investigação psicológica no campo das comunicações e relações humanas nas duas décadas seguintes.

$O$ interesse suscitado pela comunicação está intimamente relacionado com as várias características do processo social histórico, entre as quais a própria intensidade e visibilidade das novas formas de comunicação. Estas, porém, serão sempre e apenas, na expressão de Marshall McLuhan, «extensões do homem" 7, para o qual a comunicação é condição da própria sobrevivência. Sem ela, o indivíduo não vive, os organismos não funcionam, as sociedades não subsistem e as civilizações morrem. O processo comunicativo é para a pessoa o que o metabolismo é para o organismo: deles depende a própria subsistência. Não podemos deixar de comunicar. A vida individual e social, particular e pública, dos grupos e das organizações, pode resumir-se assim: dar e receber comunicação.

Dimensão de tamanha relevância, que muito é que tenha merecido o cuidado e a reflexão da pesquisa científica e a consagração do estudo académico?

Sem pretendermos estabelecer uma visão cabal do processo de formação da área científica da comunicação - o qual julgamos não estar de modo algum fechado - podemos identificar facilmente alguns elementos que prepararam a constituição deste novo campo do saber - a ciência da comunicação-que $P$. Watzlawick, em tempos não muito distantes, considerava "uma ciência na sua infância» 8. Duas ordens de fenómenos convergiram para a formação de uma área de estudos específica em torno da temática comunicacional: o advento e progressiva implantação dos meios de comunicação social ou "mass media» e a confluência de diferentes correntes de pensamento e de pesquisa científica sobre temas e problemas de comunicação. Não se trata, evidentemente, de realidades estranhas entre si, mas que, bem pelo contrário, se interpenetram e associam intimamente. Coube, no entanto, aos media o inegável papel de catalisadores de novas formas de comunicação que manifestam e caracterizam a sociedade industrial e pós-industrial. Por sua vez, a reflexão política e social, bem como a investigação científica sobre questões de

7 M. McLuhaN, Understanding Media: the Extensions of Man, N. York, Mac-Grow-Hill, 1964.

8 P. Warzlawick, Pragmática da Comunicaçăo Humana, S. Paulo, Cultrix, 9." ed., 1993, p. 13. 
comunicação no quadro de diferentes disciplinas contribuíram grandemente para a identificação da nova área de estudos e para a sua instituição académica.

\section{Os Meios de Comunicação Social}

A expressão "meios de comunicação social» corresponde aos termos ingleses "mass media» ou "meios de massa» e designa os sistemas mecanizados e electrónicos que, explorados por organizações e profissionais especializados, difundem idênticas mensagens para públicos vastos, dispersos e heterogéneos. Distinguem-se entre estes sistemas quatro categorias principais, englobando cada um deles grande variedade de modalidades: a imprensa, o cinema, a rádio e a televisão. A evolução acelerada e contínua das tecnologias de comunicação e designadamente das telecomunicações e da informática, a par das mudanças das sociedades e instituições, têm levado à criação de novos sistemas de comunicação cada vez mais potentes, móveis e adaptáveis.

$\mathrm{O}$ advento dos media, a começar pelo mais antigo, a imprensa, suscitou, naturalmente, grande atenção e preocupação às entidades sociais com poder e funções de regulação social. A comunicação generalizada, que as novas técnicas de difusão pareciam garantir, despertou esperanças e temores desmedidos que Umberto Eco tipificou na oposição e título do seu livro Apocalípticos e Integrados 9 . Para os Apocalípticos os novos meios de comunicação são causa e suporte de influência deletéria na educação, na cultura, nos costumes. Ao contrário, os Integrados reconhecem nos media grandes virtualidades para o progresso social, viabilizando por exemplo formas rápidas e eficientes de transmissão da informação e da ciência, criando assim condições favoráveis ao desenvolvimento económico e à participação democrática. Neste contexto se vislumbrou também o advento da «aldeia planetária» ou da sociedade da ubiquidade, bem como o terror da vigilância permanente do «Big Brother» 10.

A investigação científica sobre os media e seus efeitos haveria de temperar as expectativas exageradas, colocando em relevo as diferentes dimensões que caracterizam o processo psicossocial da comunicação mediática. Continua válida a conclusão formulada por M. Janowitz e R. Schulze no termo da revisão do vasto conjunto da «Communication Research» a

9 U. ECO, Appocalitici e Integrati, Milano, Bompiano, 1973.

10 Sobre este assunto ver: J. CAZENEUve, La société de l'ubiquite, Paris, Denoel, 1972; M. McLuHaN, Understanding Media, N. York, Signet Books, 1964; G. ORWEL, 1984 (Nineteen Eighty Four), London, Penguin, 1954 (1st ed. 1949). 
que procederam, ao sublinhar a natureza social do processo de comunicação através dos órgãos de difusão colectiva: «a investigação sobre os meios de massa destruiu mais que um estereótipo sobre o poder da comunicação de massa e sobre a sociedade dita de massa. Tal como outras pesquisas contemporâneas realizadas numa sociedade moderna, ela redescobriu e reafirmou a persistência das formas tradicionais da associação, da influência e do poder» 11 .

Como no passado, os media suscitam hoje o maior interesse das forças sociais, políticas, económicas e culturais. É que na «sociedade da informação", que tem nos meios de comunicação a sua expressão mais visível, não há questão social que não passe, de algum modo, pela cena mediática. Assim, cada vez menos se pode compreender uma sem compreender a outra. Daí que os media tenham desempenhado papel relevante na construção do novo campo de saber.

A constituição deste campo de reflexão sobre a comunicação, em associação com os media, mas para aquém e para além deles, não ocorreu, evidentemente, nem de modo repentino nem do nada. Processo histórico, social e cultural, integra-se na génese da sociedade a que pertence e, designadamente, na tradição e na inovação de diferentes linhas de pensamento sobre os elementos, as dimensões, e as relações da comunicação humana. Limitemo-nos a destacar entre as mais visíveis algumas das contribuições das diversas ciências para a formação da área científica da comunicação.

\section{A Matemática da Comunicação}

Ganhou valor simbólico de marco fundador na construção das Ciências da Comunicação a obra de Claude Shannon, A Teoria Matemática da Comunicação, publicada em artigo em 1948 e retomada em livro, um ano depois, com a colaboração do matemático Warren Weaver ${ }^{12}$. A teoria e o modelo de Shannon - Weaver, com conceitos rigorosamente definidos e alto grau de generalização, tornaram-se referência obrigatória para os estudos de comunicação tendo inspirado inúmeros trabalhos tanto no âmbito das Ciências, particularmente nas Engenharias de sistemas e telecomunicações, como no quadro das Ciências Sociais e Humanas. As noções de informaçāo, ruído, redundância, fonte, entre outras, foram rapidamente adoptadas por disciplinas como a Linguística, a Psicologia, a Sociologia.

11 M. JANOWITZ e R. SchlilzE «Tendances de la recherche dans le domaine des communications de masse», Communications, n. ${ }^{\circ}$, Paris, Seuil, 1981, p. 32.

12 C. SHANNON and W. WEAVER, The Mathematical Theory of Communication, Urbana, University of rllinois Press, 1949. 
O programa de Shannon - Weaver pretendeu abarcar o processo global da comunicação no qual distinguiu três níveis de questões a solucionar: a) o nível dos problemas técnicos, onde se trata da exactidão com que os símbolos podem ser transmitidos entre um emissor e um receptor; b) o nível dos problemas semânticos, ou seja, a questão da precisão com que os símbolos transmitidos veiculam o significado desejado; c) o nível dos problemas de eficiência, ou seja, a questão da eficácia com que o significado recebido influencia o comportamento no sentido pretendido.

Programa tão vasto como ambicioso haveria de revelar a maior fecundidade no âmbito do primeiro nível já que a semântica e o comportamento não caberiam no quadro teórico definido nem nas concepções que o inspiraram. Nem por isso é menor o mérito destes pioneiros cujos conceitos fundamentais permitiram uma nova compreensão dos processos humanos de comunicar e de conhecer.

Contemporânea e conexa à teoria da comunicação, desenvolveu-se a Cibernética, com destaque para a obra de Norbert Wiener ${ }^{13}$ e o contributo do próprio Weaver, o qual, em artigo de 1948, propunha a noção de "complexidade organizada" para conceber modelos de representação de certos fenómenos, não com base nos seus elementos componentes, mas a partir da sua totalidade sistemática. A Cibernética ou Teoria Geral dos Sistemas, designação esta que se imporia, inspirou importantes abordagens da comunicação humana e legou-nos conceitos originais tais como o de auto-regulação, "feed-back», inter-dependência, que permitiram avançar no conhecimento do comportamento individual e social. A este quadro de referência se pode associar o célebre trabalho sobre a saúde mental realizado por J. Ruesch e G. Bateson: Communication: the social matrix of Psychiatry ${ }^{14}$. Observe-se, de passagem, que a problemática da psiquiatria e em geral da saúde motivou importantes linhas de desenvolvimento da teoria e prática da comunicação. Refiram-se as numerosas orientações em matéria de psico-terapia, com suas teorias da personalidade, dos processos de mudança e modalidades de interacção.

Uma outra ilustração da orientação sistémica abrangendo a análise global do comportamento comunicativo ao nível do indivíduo, da relaçāo interpessoal, no quadro da organização, e na mediação tecnológica, e ainda outros importantes aspectos, é-nos facultada pela obra de Lee Thayer ${ }^{15}$.

13 N. Wiener, Cibernética e Sociedade, S. Paulo, Cultrix, 1968, (trad. de The Human Use of Human Beings, Boston, Houghton Mifflin, ed. revista de 1954 (1. ${ }^{a}$ ed. 1950)); Cybernetics or Control and Communication in the Animal and the Machine, Librairie Herman, Paris 1948; 2nd ed., N. York, MIT Press, 1961.

14 J. Ruesch and G. Bateson, Communication. The social matrix of Psychiatry, W. W. Norton and Co., 1951.

15 L. THAYER, Communication and Communication Systems, Homeword, Irwin, 1968. 


\section{Comunicação e Ciências Sociais}

Sendo a comunicação, na expressão de Ch. Cooley «, o processo através do qual as relações humanas existem e se desenvolvem» ${ }^{16}$, ou seja, através do qual as sociedades e os indivíduos se constituem e reproduzem na história humana, não podia ela deixar de merecer a consideração e, em muitos casos, o tratamento privilegiado por parte das disciplinas das Ciências Sociais e, designadamente, a Sociologia, a Psicologia e a Antropologia Cultural. Foi no quadro destas disciplinas que se formaram os fundadores da área da Comunicação com realce para o movimento da pesquisa em comunicação desenvolvida nos Estados Unidos no período do pós-guerra e décadas de 50 e 60 .

A íntima conexão do estudo da comunicação humana com as referidas disciplinas radica, por um lado, na própria natureza social da comunicação e, por outro lado, na relevante dimensão comunicativa de muitos fenómenos de ordem social, cultural e psicológica que aquelas disciplinas abordaram, criando para tanto conceitos e métodos próprios. Recordem-se os trabalhos de Antropologia Cultural, por exemplo, sobre o processo de interpenetração de cultura e personalidade, de que Ralph Linton 17 oferece instrutiva síntese, e a obra de Claude Lévi-Strauss 18 a abrir-nos novas portas para a compreensão do sentido inscrito nos mitos e outras estruturas simbólicas com que as sociedades se representam e regulam. $\mathrm{Na}$ afirmação de Edward Sapir, «...every cultural pattern and every simple act of social behavior involves communication in either an explicit or implicit sense» 19. A sociedade pode por isso ser vista como um sistema constituído pela partilha de significados, ou por uma "teia significante», na feliz expressão de D. Crowley 20. São em grande número os estudos desenvolvidos em Sociologia nos quais a comunicação se manifesta como dimensão relevante. A obra de George Herbert Mead, Mind, Self and Society bem como os ulteriores trabalhos que ela inspirou sobre o interaccionismo simbólico são bom exemplo. Em idêntico sentido integrador se pode evocar a visão de síntese que se deve a Hans Gerth e C. Wright Mills 21, e mais perto de nós, o relevo da acção comunicacional na "construção social da realidade» 22.

$16 \mathrm{CH}_{\mathrm{H}}$. Cooley, Social Organization: a study of the larger mind, N. York, Scribner's, 1909, p. 61; cit. por J. Stoetzel, La Psychologie Sociale, Paris, Flamarion, 1963, p. 11.

17 R. LINTON, The Cultural Background of Personality, N. York, Appleton, 1945.

18 Cl. Levi-Strauss, Anthropologie Structurale, Paris, Plon, 1968.

19 Cit. por D. MCQuaIL, Communication, $2^{\text {nd }}$ ed., London, Longman, 1984, p. 6.

20 D. J. CRowley, Understanding communication, The signifying web, London, Gordon, 1982.

21 H. GeRTH and C. WRIgt Mills, Character and Social Structure, N. York, Harcout, Brace and Co. 1953.

22 P. BERgER and TH. LuCKMAN, The Social Construction of Reality, London, Allen Lane, 1967. 
A abordagem da comunicação no âmbito das Ciências Sociais não se confinou aos processos de socialização e enculturação em que efectivamente tem a maior relevância. Igualmente presente nos fenómenos de influência, de liderança e de poder, nos processos de associação, de relacionamento e de interacção, na aprendizagem e na mudança, a comunicação mereceu de sociólogos e psicólogos amplo e profundo tratamento ${ }^{23}$. A obra de K. Lewin e seus discípulos, como linha mais saliente do movimento das Relações Humanas e da Dinâmica de Grupo ilustra bern esse facto. A Psicossociologia, disciplina dedicada ao estudo dos comportamentos em situação de interacção, nos grupos, nas organizações, e em contextos semelhantes, que outra coisa é senão estudo da comunicação? ${ }^{24} \mathrm{E}$ a psicologia da aprendizagem, da mudança de atitude e de comportamento? E que dizer das teorias e práticas psicoterapêuticas no concernente às estruturas e dinamismos da personalidade e aos processos de relação/comunicação entre doente/cliente e terapeuta? ${ }^{25}$ Neste vasto campo, em que as fronteiras disciplinares se revelam tão incertas, foram formuladas e confirmadas importantes noções e interpretações dos processos da comunicação humana. Razão bastante para que o estudo da comunicação prossiga em íntima associação com a pesquisa e a prática nele desenvolvidas.

\section{Comunicação, Ciências da Linguagem e Ciências Humanas}

A associação da comunicação e da linguagem nos seres humanos é tal que chegamos a confundi-las. Para o antropólogo e linguista Dell Hymes, por exemplo, a aquisição da linguagem pela aprendizagem da língua permite não só a aquisição da competência gramatical mas também a da própria competência comunicativa. Estudar a comunicação é assim, necessariamente, estudar a linguagem. Ora esta, ao contrário da comunicação enquanto tal, foi objecto de profundo e rigoroso tratamento quer no pensamento antigo grego e latino, quer no da tradição ocidental que mereceu o apelido de "logocêntrica». No entanto, como é sabido, apesar desta riquíssima herança e das reais aquisições duradoiras que ela nos legou, a

23 Os manuais de psicologia social são eloquentes a este respeito: ver, por exemplo, J. Stoetzel, La Psychologie Sociale, Paris, Flamarion, 1963.

24 Cf. por exemplo: K. LEWIN, Psychologie Dynamique, Les Relations Humains, Paris, PUF, 1972; D. CARTWRIGHT and H. ZANDER, Group Dynamics: Research and Theory, N. York, Harper and Row, 1968; M. Deursch et R. Krauss, Les Théories en Psichologie Sociale, Paris, Mouton, 1972.

25 G. AllPort, Existencial Psychology, N. York, Random House, 1965; J. FAdimen and R. Frager, Personality and Personal Growth, N. York, Harper and Row, 1976; C. Rogers, On Becoming a Person, Boston, Houghton-Mifflin, 1961. 
linguística como ciência só recentemente se impôs. O seu triunfo está na origem do extraordinário desenvolvimento das ciências da linguagem na segunda parte do nosso século.

A emergência do campo da comunicação, a seguir à II Grande Guerra, não aconteceu sob o signo da linguagem, embora esta encontrasse lugar inevitável no processo de codificação-descodificação das mensagens verbais. A orientação behaviorista que inspirou largamente a pesquisa americana em cujo seio se formou a primeira grande corrente de estudos da comunicação não favorecia a abertura às novas perspectivas da linguística e à sua influência na compreensão dos processos de comunicação humana, que são, por excelência, processos de interacção por meio de mensagens significantes. Entre estas, as mensagens verbais, ocupam lugar impar. É certo que a comunicação não coincide com a linguagem. Mas não é duvidoso que a comunicação humana se realiza, do modo mais perfeito e específico, na e pela linguagem.

Temos assim que a compreensão da comunicação passa, em importante medida, pela compreensão da linguagem. Neste sentido, conceitos e teorias elaborados no quadro da Linguística Geral, da Teoria Literária, da Teoria da Literatura, da Semiótica e de áreas interdisciplinares tais como a Sócio-linguística, a Psico-linguística, a Pragmática e as Teoria e Análise do discurso, projectaram sobre os processos comunicativos novas luzes revelando facetas que permitiram o seu melhor entendimento. A actual pesquisa permanece tão florescente que se torna difícil acompanhá-la, não só pela sua quantidade, mas também pela especificidade das teorias orientadoras e dos campos explorados. Não há, no entanto, via alternativa. Dado o carácter primordial da linguagem verbal na acção e interacção significante própria da comunicação humana, não é possível avançar na compreensão desta sem alcançar entendimento da primeira. Daí que os estudos de comunicação tenham procurado nas ciências da linguagem fundamento e orientação e mantenham com elas a mais estreita conexão. Limitando-nos a dimensões que se nos afiguram mais fecundas, parece-nos importante sublinhar os seguintes.

Os ensinamentos do fundador da linguística moderna Ferdinand de Saussure ${ }^{26}$ e os do filósofo Charles Sanders Peirce ${ }^{27}$ lançaram as bases para a progressiva elucidação dos processos de significação através dos diferentes tipos de signo e particularmente da linguagem verbal. A obra dos em 1916).

26 F. de SAussure, Cours de Linguistique Générale, Paris, Ed. Payot, 1971 (1. a publicação

27 Ch. PEIRCE, The Collected Papers of Charles Sanders Peirce, Cambridge, Mass., Harvard University Press, 1958. 
pioneiros foi continuada e completada por grande número de autores, isolados ou agrupados em «escolas», enquanto novas orientações emergiram num campo que não cessou de crescer nas últimas décadas. Na nossa perspectiva, necessariamente limitada e mesmo enviesada pelos quadros da nossa formação, destacam-se as obras e autores que permitiram avançar na explicitação e compreensão dos processos semióticos, das estruturas fundamentais da linguagem, de suas modalidades e funcionamento na interacção verbal e nos textos/discursos, sem descurar a articulação destes com as estruturas sociais. A semiótica como teoria geral da semiose constitui fundamento e quadro permanente da ciência da comunicação, definida designadamente através do pensamento não só dos fundadores já evocados mas também de autores como Charles Morris ${ }^{27}$, Louis Hjelmslev ${ }^{28}$, Roland Barthes 30, Algirdas Greimas 31, Pierre Guiraud 32, Umberto Eco 33, para referirmos apenas os que nos são mais familiares.

Por outro lado, no campo específico da linguagem, os aspectos de maior interesse sob o ponto de vista comunicacional foram recebendo tratamento cada vez mais aprofundado através de obras como as de Noam Chomski ${ }^{34}$, Roman Jakobson 35, André Martinet ${ }^{36}$, Georges Mounin 37, Émile Benveniste 38 , entre os que mais orientaram o nosso próprio estudo. A perspectiva comunicacional e intersubjectiva, já especialmente presente no último autor citado, receberia impulso decisivo através da pragmática, ou da semântica, de John Austin ${ }^{39}$ e John Searle ${ }^{40}$ que nos chegaram principalmente por intermédio dos trabalhos de Oswald Ducrot ${ }^{41}$. Uma entre

$28 \mathrm{Ch}$. MORRIS, Writings on the General Theory of Signs, Ths Hague, Mouton, 1971 (reúne textos anteriores de 1938, 1946, 1964).

29 L. HJelmslev, Prolégomènes à une théorie du langage, Paris, Minuit, 1966, (trad. du danois, 1943).

30 R. BARTHES, "Elements de Sémiologie», Communications, n. ${ }^{\circ} 4$, Seuil, 1961; Mythologies, Paris, Seuil, 1957.

31 A. Gremas, Sémantique Structurale, Paris, Larousse, 1966; Du Sens, Paris, Seuil, 1970; Sémiotique et Sciences Sociales, Paris, Seuil, 1976; Sémiothique, Dictionnaire raisonné de la theorie du langage, Paris, Hachette, 1979.

32 P. GunRaud, la Sémiologie, Paris , PUF, 1971.

33 U. Eco, Le forme del contenuto, Milano Bompiano, 1971; Trattato di Semiótica Generale, Milano, Bompiano, 1976.

34 N. СномSкI, Sintactic Structures, The Hague, Mouton, 1957.

35 R. JAKOBSON, Essais de Linguistique Génerale, Paris, Minuit, 1963.

36 A. MARTINEr, Eléments de Linguistique Générale, Paris, Colin, 1968.

37 G. Mounin, La Sémantique, Paris, Seghers, 1972.

38 E. Benveniste, Problèmes de Lingusitique Générale, Vol. I, Paris, Gallimard, 1966.

38 J. AustuN, How to do things with words, Oxford, Clarendon Press, 1962.

40 J. SEARL, Speech Acts, Cambridge, Univ. Press, 1969.

41 O. Ducrot, Le Structuralisme en Linguistique, Paris, Seuil, 1968; Le Dire et le dit, Paris, Minuit, 1984; Dictionnaire Encyclopédique des Sciences du Langage, Paris, Seuil, 1971. 
muitas das recentes e actuais correntes do pensamento científico sobre a língua e sobre a comunicação, a que fica evocada, pese embora a sua marca pessoal, não deixa de indiciar claramente a sua íntima associação.

A relação da comunicação com a linguagem projecta-se na relação da linguagem com o pensamento, implicados no mesmo processo que é a génese da significação. Daí que o estudo da comunicação, como o da linguagem, mantenha íntima conexão com as ciências do espírito ou Ciências Humanas e designadamente com a filosofia e disciplinas específicas afins. Tratando-se na comunicação, como efectivamente se trata, de criar e/ou descobrir sentido, como não haveria de verificar-se a referida conexão? Daí o encontro com as correntes de pensamento que procuram de um modo ou outro os percursos da interpretação e da génese do sentido. Com efeito, a temática comunicacional encontra eco profundo na fenomenologia, na hermenêutica, na filosofia social e política, como é patente, não só nas obras de referência já clássicas como na reflexão actual. $O$ interesse suscitado, por exemplo, pela obra de Habermas sobre a comunicação, é bem revelador. No mesmo sentido, o renascer da retórica e das teorias da argumentação adquirem valor simbólico sobre a manifestação da centralidade da comunicação no pensamento contemporâneo.

\section{A interdisciplinaridade das ciências da comunicação}

As disciplinas e linhas de reflexão evocadas estabeleceram os fundamentos da área científica da comunicação que nelas continua a procurar os seus quadros teóricos e metodológicos. Outras abordagens poderiam ser referidas, como por exemplo, a tradição dos departamentos das Universidades Americanas dedicados ao estudo e formação nas disciplinas do discurso (Speech communication) os quais desempenharam importante papel na criação de departamentos de comunicação ${ }^{42}$. Uma corrente de reflexão e análise relevante na nova área é a que se refere à comunicação pela imagem, a qual conhecera já notório desenvolvimento com o cinema e haveria de suscitar o maior interesse com a explosão das técnicas audiovisuais de que, por exemplo, a publicidade vem tirando o maior proveito. Outras dimensões do processo comunicativo, a suscitar também análises específicas e originais, foram as relativas à expressão corporal, incluindo,

42 A actual "Speech Communication Association", assim designada desde 1968, foi criada em 1914 com o nome de «National Association of Academic Teachers of Public Speaking». Cfr. G. GERBNER/W. Schram, "Study of Communications», Intemational Encyclopedia of Communications, Oxford Univ. Press., 1989, Vol. I, p. 360. 
movimentos, gestos, posições e relações espaciais e temporais. Neste sentido vão, entre outros, os trabalhos de Erwing Goffman ${ }^{43}$, Edward Hall ${ }^{44}$, Ray Birdwhistel ${ }^{45}$, que deram justo relevo à significação daquelas dimensões da interacção comunicativa.

Como anteriormente já referimos, a partir dos fins da II Grande Guerra, a importância da comunicação e a sua expansão, sob suas múltiplas formas, nos seus diferentes elementos e dimensões, nas suas conexões com toda a esfera da vida social, não cessou de crescer, e crescer a um ritmo cada vez mais acelerado. A complexidade do processo comunicativo e a multiplicidade das suas realizaçōes levaram a abordagens muito diferenciadas, quer sob o ponto de vista teórico e metodológico, quer sob o ponto de vista das práticas. A tal ponto que, em nossos dias, o campo da comunicação, de tão extenso, sincrético e ambíguo, corre riscos de indefinição e descaracterização. Não se trata todavia, de tendência inequívoca e movimento imparável. Bem pelo contrário, a incontestável importância da comunicação para a vida dos humanos e de suas sociedades exige o trabalho metódico rigoroso e continuado em prol da compreensão aprofundada do processo da comunicação humana e do seu consequente aperfeiçoamento.

O campo das Ciências da Comunicação apresenta-se, pois, muito vasto, com limites mal definidos, atravessado por forças contrárias que ora o revigoram ora o enfraquecem. Neste contexto, impõe-se tomar orientação prudente mas com abertura bastante às diferentes abordagens e abrangendo as temáticas e aspectos específicos do comportamento comunicativo. O carácter sincrético daí resultante pode não favorecer, é certo, a coerência teórica, em princípio sempre desejável para uma disciplina. Mas tem o mérito não negligenciável de reconhecer a real pluralidade dos saberes e abordagens sobre a comunicação humana, que, por sua vez, exprimem a complexidade dos processos que a realizam.

É ponto geralmente aceite que não dispomos de uma teoria unitária sobre a comunicação humana. As proclamações em contrário que alguns ousaram não se revelaram fundamentadas. E verdade que o grave risco da falsa interdisciplinaridade espreita a nossa disciplina. Entendemos a interdisciplinaridade como humilde prática científica que procura e aceita ferramentas conceituais de diferentes disciplinas, desde que se mostrem adequadas para tratar questões específicas, abordadas, por isso mesmo,

43 E. Goffman, The Presentation of Self in Every Day Life, N. York, Doubleday, 1959; Frame Analysis, Mass., Havard, Univ. Press, 1974.

44 E. HaLl, The Silent Language, N. York, Doubleday, 1959.

45 R. Birdwhistel, Kinesics and Context, Filadelfia, Univ. of Pennsylvania Press, 1970. 
num quadro próprio. Essencial é que a importação de conceitos e teorias não traia a sua natureza e validade e que a interdisciplinaridade não redunde no empobrecimento das disciplinas em causa, mas promova, antes, a sua convergência para abordagens mais adequadas à complexidade das questões em análise. Tal é, em todo o caso, a concepção que perfilhamos e que pode permitir o tratamento científico das questōes da comunicação humana sem truncar nem a natureza desta nem o valor fundado das disciplinas constituídas.

Pela nossa parte, não desejamos tomar a posição daqueles que, caracterizando a questão comunicacional como moda, ideologia, terra de ninguém, refúgio ou tapa-buracos, chegam a propor o abandono da própria noção de comunicação ${ }^{46}$. Pretendemos antes apostar na via positiva de prosseguir o exame dos fenómenos do comportamento humano que a linguagem comum foi designando por comunicação. A presença multímoda da comunicação em larguíssima gama de fenómenos da experiência humana, longe de inibir ou desincentivar a sua abordagem científica, haverá antes de a motivar. Extensão tão ampla de conceito a que naturalmente corresponde uma compreensão ou conteúdo de grande generalidade pode precisamente revelar os traços essenciais dos processos de comunicação. De todo o modo, não é duvidoso que o processo de comunicação, através do qual os seres humanos compreendem e se fazem compreender por meio de signos, seja princípio e fundamento de toda a vida pessoal e social. Abordá-lo e compreendê-lo o mais adequadamente possivel é tributar-lhe a devida consideração e abrir caminhos para sua mais cabal realização na acção individual e colectiva. Da comunicação, da competência comunicativa dos indivíduos, dos grupos, das sociedades, depende a sua existência e a qualidade desta. Não podemos deixar de comunicar, e, nos nossos modos de comunicar, manifesta-se e constrói-se o nosso modo de ser. É inegável, e a experiência comprova, que o estudo da comunicação humana se revela caminho difícil, pedregoso, acidentado e incerto. Os que hoje nos aventuramos nele, crentes no valor do objecto procurado e decididos a percorrer os trilhos de métodos adequados, não faremos sós a viagem. Outros abriram já sendas e clareiras, construíram pontes, fixaram marcos e direç̧ões que nos permitem traçar o nosso caminho, o qual em procuras desta natureza, sempre haverá de ser próprio.

46 E. Verón, «Pour en finir avec la communication», Réseaux, n. ${ }^{\circ} 46-47$, Paris, CNET (1991), p. 122. 